\title{
El mercado laboral en la frontera norte de México: estructura y políticas de empleo Jorge Eduardo Mendoza*
}

\section{Resumen}

El estudio analiza los factores que han impactado el mercado de trabajo y el empleo en los estados de la frontera norte y las principales ciudades de esa región. Se relaciona el patrón del crecimiento económico seguido por la economía mexicana con el mercado laboral de la región. Se destacan las políticas de empleo nacional y en la región de la frontera norte en los últimos años y se analizan sus ventajas y limitaciones. Las tasas de desempleo abierto en la frontera norte han sido menores a las de otras regiones, aunque existe presión por incorporar la creciente población económicamente activa. Resaltan la capacitación en Baja California y Nuevo León, los cuales han ofrecido cursos requeridos por las empresas en áreas técnicas, industriales y administrativas. Las políticas de empleo han sido un instrumento para canalizar recursos del Estado, pero sólo han logrado combatir el desempleo parcialmente, pues su naturaleza anticíclica les impide impactar efectivamente en el desempleo. El combate al desempleo requiere un esfuerzo para generar educación y capacitación acorde con las necesidades de las empresas.

Palabras clave: Mercados laborales, empleo, frontera, manufacturas, política de empleo.

\begin{abstract}
The study analyzes the factors that have impacted the labor market and employment in the northern border of Mexico and in its most important border cities. The economic growth of the region is related to the labor market. Additionally, the most important employment policies, both at the national and the regional level, are described showing their advantages and limitations. It is shown that the rates of open unemployment are lower in the northern border, although there is an important pressure to provide employment for the increasing labor force. With respect to training, the states of Baja California and Nuevo Leon stand out for their industrial, technical and managerial courses. The employment polices have been an important tool for offsetting the increasing unemployment rates but have been only a partial instrument, since structural reforms in education and infrastructure development are required to promote investment and create employment.
\end{abstract}

Keywords: Labor markets, employment, border region, manufactures, employment policy.

* Investigador del Departamento de Estudios Económicos, El Colegio de la Frontera Norte; miembro del Sistema Nacional de Investigadores de México, Nivel II. Correo electrónico: emendoza@colef.mx 


\section{Introducción}

Desde la instrumentación del Tratado de Libre Comercio de América del Norte (TLCAN) el primero de enero de 1994, el comercio y la inversión han sido factores importantes del crecimiento económico de México y, en particular, de la región de la frontera con Estados Unidos. No obstante que la economía mexicana experimentó un rápido dinamismo durante la década de los noventa, los indicadores de empleo muestran la existencia de una incapacidad del mercado laboral para absorber la demanda de empleo, lo que ha determinado que el desempleo y el subempleo, y la migración hacia Estados Unidos, sean algunas de las principales características del mercado laboral del país.

Como consecuencia de los cambios en la política económica derivada de la apertura comercial, la economía mexicana experimentó modificaciones en la dinámica y las características del empleo laboral que determinaron una caída del empleo como resultado del cierre de empresas privadas y públicas afectadas por la competencia externa y la caída de la inversión pública (Revenga, 1995). Posteriormente, se ha observado una insuficiencia en la generación del empleo total y de empleos de mayor calificación y remuneración, lo que se ha convertido en una constante del modelo de crecimiento económico. Este fenómeno ha generado importantes presiones a las políticas laborales.

Adicionalmente, se destaca que como resultado de la creciente integración de la economía mexicana a la de Estados Unidos, los niveles de desempleo formal de la economía mexicana se han reducido, en particular, en los estados de la frontera norte de México. No obstante, esta disminución del desempleo se encuentra acompañada de un incremento de trabajos temporales, de baja productividad y de salarios reducidos. Además, se aprecia que la participación de los salarios con prestaciones se ha reducido en el total del empleo.

Por tanto, la economía mexicana se caracteriza por contar con una fuerza laboral de más de 40 millones de personas que ha crecido a un promedio anual superior al 3\%, lo cual ha presionado al mercado laboral. Lo anterior ha sido producto de la incapacidad del aparato productivo para generar empleos al mismo ritmo de crecimiento de la población eco-

nómicamente activa (PEA), lo que ha generado la brecha existente entre la 
demanda y la oferta de empleo de México. Lo anterior ha derivado en los siguientes fenómenos en el mercado laboral:

a) El crecimiento de las actividades económicas realizadas mediante el empleo informal.

b) El aceleramiento de los flujos de trabajadores mexicanos que migran hacia la frontera norte para emplearse en las maquiladoras o para cruzar hacia Estados Unidos.

c) El aumento del dinamismo del empleo formal en las actividades industriales y manufactureras (incluidas las maquiladoras) a lo largo de los estados de la frontera norte. En particular, se destacan las actividades de la industria maquiladora de exportación en los centros urbanos localizados a lo largo de la frontera México-Estados Unidos.

Para hacer frente a este fenómeno, el gobierno federal y los gobiernos estatales han establecido diferentes programas para reducir el desempleo y la falta de capacitación de los trabajadores. No obstante, el grado de efectividad que han tenido éstos ha sido limitado, ya que en algunas regiones del país se observan niveles elevados de desempleo y, en general, este fenómeno también se aprecia a escala nacional.

El presente estudio está orientado a presentar los factores económicos que han delineado el mercado de trabajo y el empleo en los estados de la frontera norte y las principales ciudades de esa región. En ese sentido, el documento relaciona las características del patrón del crecimiento económico seguido por la economía mexicana con el comportamiento del mercado laboral en términos del empleo a nivel nacional y a nivel de la región de la frontera norte del país. Finalmente, se presenta un apartado que resume las principales políticas de empleo a nivel nacional y regional seguidas en México en los últimos años y se analizan las ventajas y limitaciones de ese tipo de políticas laborales.

\section{El desempeño económico y sus repercusiones en el empleo de México}

La economía de México experimentó un largo proceso de crecimiento económico desde la última recesión de 1994 hasta finales del año 2008. En 
particular, se aprecia que los estados de la frontera norte de México han tenido un mayor dinamismo relativo en el crecimiento. De esta manera, mientras que la economía de México en su conjunto creció a una tasa promedio de $2.9 \%$ en el periodo 1993-2006, la región que comprende todos los estados de la frontera norte creció a una tasa de $4.1 \%$, destacándose por su rápido crecimiento los estados de Baja California, Chihuahua y Nuevo León. ${ }^{1}$

Las condiciones que permitieron esta mayor integración están relacionadas con la proximidad geográfica entre esta región y Estados Unidos; por otra parte, en estados como Nuevo León y Coahuila una condicionante decisiva se relacionó con la base industrial y manufacturera ya establecida previamente en estos estados, y generada por la industrialización por el proceso de sustitución de importaciones seguido por México desde la década de los cuarenta hasta finales de la de los setenta.

Cabe destacar que la región de la frontera norte se convirtió en un polo de atracción para la inversión extranjera directa (IED), en especial de la inversión proveniente de Estados Unidos. El crecimiento de los flujos de la IED en México entre 1994 y 2007 fue de 5.9\%. ${ }^{2}$ No obstante, el promedio de crecimiento de la captación de IED en algunos estados de la región de la frontera norte fue superior a lo captado a nivel nacional. Así, estados como Chihuahua, Baja California, Nuevo León y Sonora tuvieron tasas de crecimiento promedio en el periodo mucho más aceleradas que el total nacional. Las altas tasas de crecimiento fueron consecuencia de la entrada masiva de inversiones orientadas a la industria maquiladora de exportación. Por su parte, el estado de Nuevo León también recibió inversiones en el área de maquiladoras, y en las manufacturas de exportación no incorporadas al régimen de maquila. Se destaca que, en particular, la IED que se localizó en la frontera norte se relacionó con inversiones en plantas maquiladoras de poca intensidad de capital para aprovechar ventajas de costos salariales y proximidad geográfica. Cabe destacar que además de las inversiones provenientes de Estados Unidos, se aprecia una fuerte IED

1 Elaboración propia con datos del Instituto Nacional de Estadística, Geografía e Informática (INEGI).

2 Banco de Información Económica (BIE) del INEGI. 


\section{Cuadro 1}

Exportaciones no petroleras, 1994-2007 (Millones de dólares)

\begin{tabular}{|r|r|r|r|r|}
\hline & \multicolumn{1}{|c|}{ Total } & Agropecuarias & Extractivas & Manufactureras \\
\hline 1994 & $\$ 53,252.0$ & $\$ 3,058.7$ & $\$ 372.6$ & $\$ 49,820.7$ \\
\hline 1995 & $\$ 70,858.7$ & $\$ 4,581.4$ & $\$ 488.2$ & $\$ 65,789.1$ \\
\hline 1996 & $\$ 84,160.1$ & $\$ 4,129.4$ & $\$ 421.0$ & $\$ 79,609.5$ \\
\hline 1997 & $\$ 98,953.8$ & $\$ 4,448.7$ & $\$ 450.1$ & $\$ 94,055.1$ \\
\hline 1998 & $\$ 110,232.4$ & $\$ 4,335.5$ & $\$ 447.6$ & $\$ 105,449.2$ \\
\hline 1999 & $\$ 126,391.7$ & $\$ 4,456.0$ & $\$ 421.2$ & $\$ 121,514.6$ \\
\hline 2000 & $\$ 149,985.8$ & $\$ 4,765.4$ & $\$ 496.0$ & $\$ 144,724.6$ \\
\hline 2001 & $\$ 145,580.4$ & $\$ 4,446.3$ & $\$ 385.4$ & $\$ 140,748.5$ \\
\hline 2002 & $\$ 146,216.1$ & $\$ 4,214.5$ & $\$ 367.1$ & $\$ 141,634.8$ \\
\hline 2003 & $\$ 146,164.2$ & $\$ 5,035.5$ & $\$ 496.3$ & $\$ 140,632.1$ \\
\hline 2004 & $\$ 164,332.0$ & $\$ 5,683.8$ & $\$ 900.8$ & $\$ 157,747.3$ \\
\hline 2005 & $\$ 182,342.3$ & $\$ 6,008.2$ & $\$ 1,167.8$ & $\$ 175,166.2$ \\
\hline 2006 & $\$ 210,903.2$ & $\$ 6,852.7$ & $\$ 1,316.8$ & $\$ 202,733.5$ \\
\hline 2007 & $\$ 228,857.1$ & $\$ 7,435.2$ & $\$ 1,736.9$ & $\$ 219,684.5$ \\
\hline TCPA & $11.22 \%$ & $6.83 \%$ & $11.84 \%$ & $11.41 \%$ \\
\hline
\end{tabular}

Fuente: Grupo de trabajo integrado por INEgi-Banxico-SAT (Servicio de Administración Tributaria) y la Secretaría de Economía.

de la región de Asia (Japón, China, Taiwán y Corea) que se orientó fundamentalmente a los estados de la frontera norte $(51.9 \%) .^{3}$

La estrategia de crecimiento basado en las exportaciones manufactureras iniciada desde finales de la década de los ochenta, se profundizó con el establecimiento del TLCAN firmado por Canadá, Estados Unidos y México. Lo anterior resultó en un rápido crecimiento de las exportaciones no petroleras, particularmente de las exportaciones manufactureras y maquiladoras (cuadro 1). Este patrón de crecimiento económico de México tuvo como efecto dinamizar la economía de la frontera, aunque la expansión maquiladora no ha logrado generar cadenas productivas sólidas que expandan el mercado interno debido a que la meta principal de la pro-

3 De acuerdo a estimaciones con base en información de la Secretaría de Economía, Dirección General de Inversión Extranjera. 
ducción del sector se ha orientado, casi totalmente, al mercado de Estados Unidos. No obstante, el crecimiento experimentado en la región estimuló la creación del empleo en la industria maquiladora y las actividades exportadoras.

\section{La transformación del mercado laboral en México}

En el periodo de apertura el empleo total en México experimentó un significativo crecimiento de 3.2 millones de empleos entre 1991 y 1994, y de 5.2 millones entre 1994 y 1999 (Malacon y Expositi, 2003). Asimismo, como resultado de la apertura económica en la década de los noventa, se experimentó un importante crecimiento del empleo industrial y manufacturero, del sector servicios y, de manera más moderada, del sector de la construcción.

Kaplan, Martínez y Robertson (2007) estimaron que las recesiones económicas de 1995 y 2001 afectaron los mercados de trabajo por diferentes causas. La primera recesión se relacionó con problemas de falta de crédito interno que afectó pequeños negocios; la segunda se relacionó con la recesión económica de Estados Unidos y la caída de la producción manufacturera en ese país, que afectó a la mayoría de las grandes empresas que operan en México, particularmente en la frontera.

Así, a partir del año 2001 se aprecia que el comportamiento del empleo en la economía mexicana mostró una reducción del ritmo de crecimiento el cual cayó a una tasa del $0.2 \%$ pasando de 37.59 millones de personas a 37.68 millones (cuadro 2). En particular, se observan caídas importantes en el sector industria en su conjunto, las manufacturas, la minería y el sector de la construcción. A partir de ese año, la dinámica del empleo total en México muestra un estancamiento relativo, alcanzando una tasa de crecimiento promedio anual de $1.8 \%$ entre el 2000 y el 2007. Además, se aprecia una franca declinación del empleo en el sector agrícola de $-2 \%$ y un crecimiento muy lento del empleo en el sector de las manufacturas.

Considerando que las manufacturas han sido uno de los pivotes fundamentales del crecimiento basado en la estrategia exportadora, la apertura económica y la integración al mercado estadounidense, la reducción de la capacidad de generación de empleo en este sector y del sector 


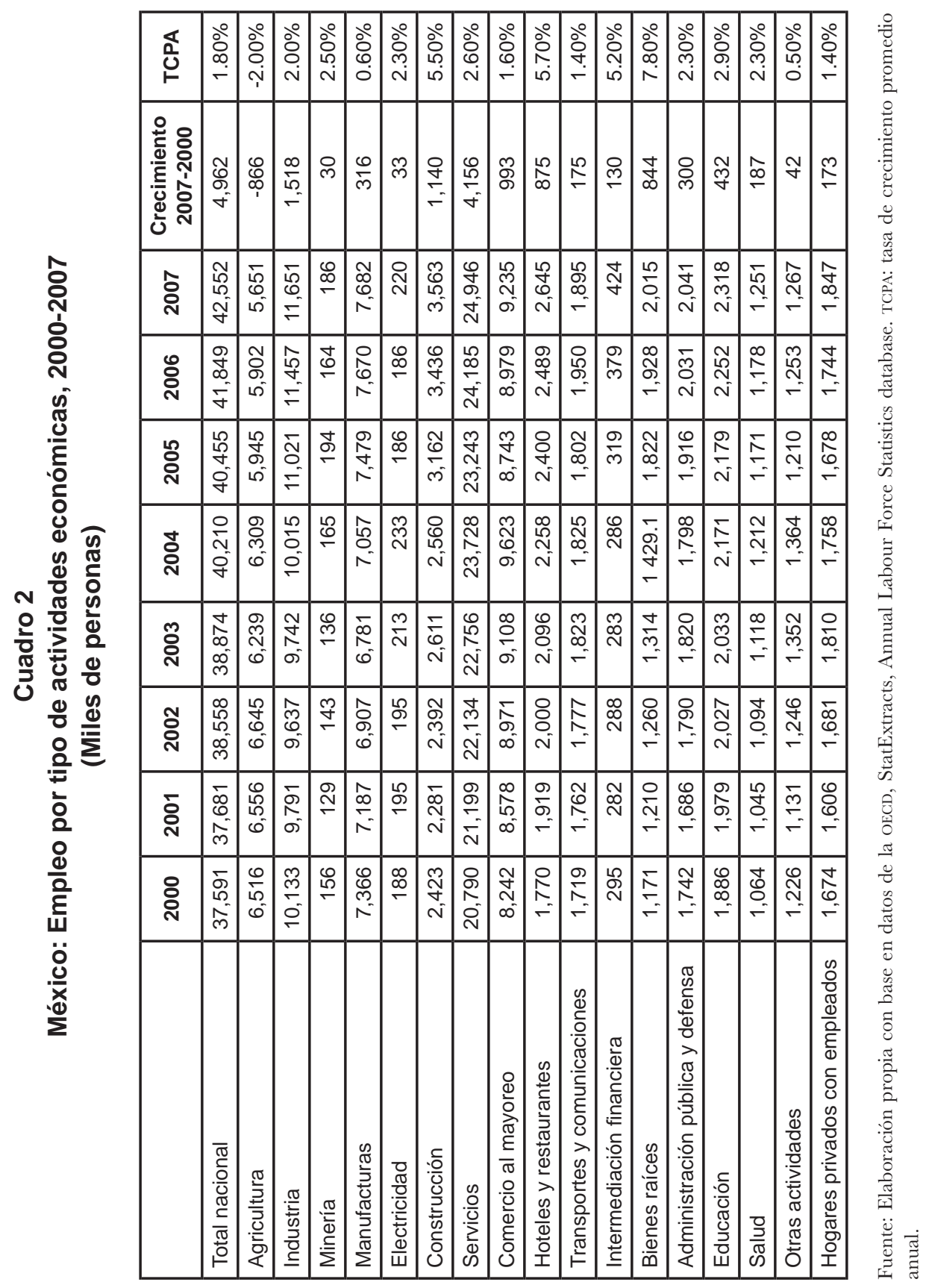


agrícola parecen reflejar el agotamiento del modelo de crecimiento sustentado en el sector exportador. Asimismo, debido a que la localización geográfica del dinamismo manufacturero y exportador de la década de los noventa se ubicó en los estados de la frontera norte de México, el impacto de la desaceleración de la economía estadounidense ha derivado en un mayor estancamiento del empleo en la región que hace frontera con Estados Unidos.

\section{Integración económica y mercado laboral en la frontera norte}

De acuerdo con algunos estudios (Zadia, 2001), la apertura económica inicialmente no trajo efectos sustanciales en el crecimiento del empleo y en los salarios. Sin embargo, el modelo de crecimiento económico de México basado en la integración económica con Estados Unidos ha tenido impactos diferenciados favoreciendo a algunos sectores en detrimento de otros y, además, ha permitido el desarrollo relativo de algunas regiones, como la fronteriza, en relación con las tradicionales regiones económicamente más dinámicas, como la del centro del país. De acuerdo con Hanson (2003), el ajuste regional ha tenido un impacto decisivo en los mercados regionales favoreciendo a los salarios y el empleo de los trabajadores mexicanos localizados en la frontera norte de México o las actividades de mayor calificación del trabajo (Meza, 2005).

Por su parte, Robertson (2000) estimó que el mercado laboral de México y Estados Unidos ha venido integrándose incluso desde antes de la firma del TLCAN -en particular en la frontera norte de México, donde se presentan respuestas más fuertes a los impactos salariales provenientes de los Estados Unidos-. Por su parte, Cortez e Islas (2007) corroboran que después de 1994, y como resultado del establecimiento del TLCAN, se aceleró la integración del mercado laboral entre la región norte de México y la del sur de Estados Unidos. Dicha integración se ha traducido en un cambio del comportamiento del empleo y del salario manufacturero entre ambos países tanto en el corto como en el largo plazos. Los autores señalan que después de 1994 se presentó un movimiento paralelo en las tasas de crecimiento del empleo en ambas regiones fronterizas de los países. Además, el comportamiento de salarios y empleo profundizó su dependencia respecto al comportamiento de la economía de Estados Unidos, por lo que 
las políticas de empleo de México por sí mismas no resultan tan efectivas en el contexto de la actividad de las empresas estadounidenses que trabajan en ambos lados de la frontera.

Se puede señalar que el mercado laboral de la frontera norte se diferencia por contar con un acelerado crecimiento del empleo manufacturero y, en algunos estados, por la existencia de una baja tasa de desempleo. De acuerdo con Frenkel y Ros (2004), la economía mexicana absorbió parte de la fuerza de trabajo desplazada por la apertura económica y la penetración de importaciones mediante la expansión de la industria maquiladora.

De esta manera, una característica del empleo en la frontera norte se refiere a su dinamismo en el sector manufacturero. Con base en los Censos de Población de 1980, 1990 y 2000, se aprecia que la participación de la fuerza de trabajo en el sector manufacturero en el ámbito nacional se elevó de $11.7 \%$ en 1980 hasta 19\% en el 2000. No obstante, la región fronteriza de México (compuesta por ciudades que se encuentran en la línea fronteriza o a menos de 200 kilómetros) mostró un mayor dinamismo, pasando de $15.5 \%$ a $34.6 \%$ del total del empleo en la región en el mismo periodo (cuadro 3 ).

La mayor concentración de empleo en el sector manufacturero de los estados de la frontera norte está relacionada con el crecimiento de las plantas manufactureras altamente exportadoras, como es el caso de la industria del automóvil en Monterrey y Saltillo, y con las plantas que se dedican solamente a ensamblar insumos para reexportación, las cuales surgieron bajo el régimen de maquiladora a lo largo de las principales ciudades de la frontera norte.

Las características regionales del crecimiento manufacturero en la frontera norte muestran que los principales estados con mayor participación en la industria manufacturera en el año 2000 fueron Chihuahua con $33.8 \%$, Coahuila con 32.\%, Baja California con $28.3 \%$ y Nuevo León con $28.4 \%$. En menor medida, pero con importante participación en el sector manufacturero, se encuentran Sonora y Tamaulipas. Finalmente, las principales ciudades localizadas a lo largo de la frontera con Estados Unidos mostraron elevados porcentajes de participación del empleo en el sector manufacturero; en particular se destacan Ciudad Juárez con 46.3\%, Matamoros con $39.9 \%$, Reynosa con $36.4 \%$, Nogales con $43.7 \%$ y Acuña con 54.5 por ciento. 


\section{Cuadro 3}

\section{Participación de la fuerza de trabajo en el sector manufacturero de México}

\begin{tabular}{|c|c|c|c|}
\hline & 1980 & 1990 & 2000 \\
\hline México & $11.7 \%$ & $19.2 \%$ & $19.0 \%$ \\
\hline Región fronteriza & $15.5 \%$ & $28.2 \%$ & $34.6 \%$ \\
\hline Baja California & $13.6 \%$ & $23.2 \%$ & $28.3 \%$ \\
\hline Tijuana & $16.7 \%$ & $28.8 \%$ & $32.0 \%$ \\
\hline Tecate & $20.3 \%$ & $39.5 \%$ & $38.8 \%$ \\
\hline Mexicali & $11.3 \%$ & $18.5 \%$ & $25.4 \%$ \\
\hline Baja California frontera & $14.1 \%$ & $24.9 \%$ & $29.8 \%$ \\
\hline Sonora & $9.6 \%$ & $16.1 \%$ & $19.5 \%$ \\
\hline San Luis Río Colorado & $8.9 \%$ & $16.9 \%$ & $23.4 \%$ \\
\hline Puerto Peñasco & $8.4 \%$ & $1.4 \%$ & $8.4 \%$ \\
\hline Nogales & $25.0 \%$ & $40.4 \%$ & $43.7 \%$ \\
\hline Cananea & $8.6 \%$ & $7.3 \%$ & $17.6 \%$ \\
\hline Naco & $11.6 \%$ & $34.2 \%$ & $25.7 \%$ \\
\hline Agua Prieta & $28.1 \%$ & $39.3 \%$ & $31.7 \%$ \\
\hline Sonora frontera & $14.9 \%$ & $17.1 \%$ & $27.0 \%$ \\
\hline Chihuahua & $12.4 \%$ & $26.4 \%$ & $33.8 \%$ \\
\hline Janos & $2.2 \%$ & $9.4 \%$ & $12.3 \%$ \\
\hline Ascensión & $5.8 \%$ & $21.9 \%$ & $20.4 \%$ \\
\hline Ciudad Juárez & $21.6 \%$ & $41.3 \%$ & $46.3 \%$ \\
\hline Guadalupe & $7.3 \%$ & $33.6 \%$ & $43.6 \%$ \\
\hline P.G. Guerrero & $3.1 \%$ & $30.9 \%$ & $45.0 \%$ \\
\hline Ojinaga & $4.8 \%$ & $7.4 \%$ & $17.5 \%$ \\
\hline Manuel Benavides & $3.2 \%$ & $1.3 \%$ & $1.8 \%$ \\
\hline Chihuahua frontera & $20.0 \%$ & $39.7 \%$ & $45.1 \%$ \\
\hline Coahuila & $14.4 \%$ & $25.6 \%$ & $32.0 \%$ \\
\hline Ocampo & $6.2 \%$ & $39.2 \%$ & $31.0 \%$ \\
\hline Acuña & $18.3 \%$ & $42.7 \%$ & $54.5 \%$ \\
\hline Jiménez & $3.7 \%$ & $35.7 \%$ & $47.4 \%$ \\
\hline Piedras Negras & $15.4 \%$ & $29.9 \%$ & $35.8 \%$ \\
\hline Guerrero & $6.8 \%$ & $10.3 \%$ & $18.8 \%$ \\
\hline Nava & $11.5 \%$ & $11.4 \%$ & $26.7 \%$ \\
\hline
\end{tabular}

(continúa...) 
(...continuación)

\section{Cuadro 3}

Participación de la fuerza de trabajo en el sector manufacturero de México

\begin{tabular}{|l|c|c|c|}
\hline & $\mathbf{1 9 8 0}$ & $\mathbf{1 9 9 0}$ & $\mathbf{2 0 0 0}$ \\
\hline Coahuila frontera & $14.7 \%$ & $32.8 \%$ & $43.0 \%$ \\
\hline Nuevo León & $24.5 \%$ & $29.8 \%$ & $28.4 \%$ \\
\hline Anáhuac & $4.4 \%$ & $13.9 \%$ & $22.4 \%$ \\
\hline Nuevo León frontera & $4.4 \%$ & $13.9 \%$ & $22.4 \%$ \\
\hline Tamaulipas & $11.9 \%$ & $19.0 \%$ & $23.3 \%$ \\
\hline Nuevo Laredo & $13.2 \%$ & $25.2 \%$ & $23.6 \%$ \\
\hline Miguel Alemán & $9.6 \%$ & $11.0 \%$ & $11.5 \%$ \\
\hline Camargo & $9.0 \%$ & $16.6 \%$ & $29.7 \%$ \\
\hline Gustavo Díaz Ordaz & $6.4 \%$ & $10.7 \%$ & $26.6 \%$ \\
\hline Reynosa & $15.6 \%$ & $25.0 \%$ & $36.4 \%$ \\
\hline Río Bravo & $8.9 \%$ & $23.6 \%$ & $27.5 \%$ \\
\hline Valle Hermoso & $6.6 \%$ & $12.7 \%$ & $26.6 \%$ \\
\hline Matamoros & $17.7 \%$ & $37.9 \%$ & $39.9 \%$ \\
\hline Tamaulipas Frontera & $14.1 \%$ & $27.8 \%$ & $32.8 \%$ \\
\hline
\end{tabular}

Fuente: Elaboración propia con base en las estimaciones de los Censos de Población 1980, 1990 y 2000.

Así pues, como resultado del patrón de crecimiento, se aprecia que el mercado laboral de la región de la frontera norte de México presenta características diferenciadas respecto al resto de los estados. En primer término, se aprecia que la estructura de ocupación en los estados de la frontera norte se relaciona con la estrategia de promoción de las exportaciones manufactureras, ya que los índices de localización del empleo ocupado en el sector secundario son superiores a los del resto de los estados. Por su parte, la región frontera norte se caracteriza por estar menos especializada en la producción agrícola en relación con el resto del país. ${ }^{4}$

4 Frontera norte: comprende los estados de Baja California, Sonora, Chihuahua, Coahuila, Nuevo León y Tamaulipas. Resto del país: comprende el resto de los estados y el D.F. Elaboración propia con datos de la ENOE, 2009. 
Una segunda característica a destacar es que las tasas de desempleo abierto de los estados de la frontera norte de México son menores a las experimentadas en otras regiones del país. Así, la tasa de desempleo abierto de la región frontera norte alcanzó 3.7\% en 2005 y se incrementó a $4.4 \%$ en 2008. No obstante, la presión ejercida por el incremento de la PEA se refleja de manera más directa por la tasa de desocupación parcial y desocupación ${ }^{5}$ que incluye no sólo la desocupación sino también la sub-ocupación que se experimenta por trabajadores que no pueden ocuparse en empleos de tiempo completo. Dicha tasa fue superior a la tasa de desempleo abierto, alcanzando $8.3 \%$ en 2005 y $10.6 \%$ en el primer trimestre de 2008. Asimismo, la tasa de condiciones críticas de ocupación alcanzó $7.3 \%$ y $6.1 \%$ en el periodo referido,${ }^{6}$ demostrando la creciente problemática de desempleo que se experimenta en la región (cuadro 4).

En cuanto al análisis de las condiciones regionales de ocupación de la fuerza laboral en los diferentes estados que conforman la región de la frontera norte de México, se aprecia que Baja California mostró las tasas más bajas de desocupación seguida por Chihuahua y Tamaulipas.

En lo que toca al porcentaje de trabajadores que eran asalariados en el sector formal, Nuevo León y Coahuila mostraron las mayores participaciones, lo que demuestra que dichas economías absorbieron mayores niveles de empleo asalariado. Un aspecto importante del mercado de trabajo fronterizo es la creciente necesidad de generar empleos que puedan absorber la demanda derivada del crecimiento de la PEA. De acuerdo con las proyecciones de la población realizadas por el Consejo Nacional de Población (Conapo), entre 2005 y 2008 la PEA de los estados de la frontera norte se incrementaría en un promedio anual de 281400 personas. No obstante, el crecimiento promedio anual para la población que sería empleada en el sector formal de la economía era de sólo 163 854, lo que

\footnotetext{
5 Porcentaje de la PEA que se encuentra desocupado, más la ocupada que trabajó menos de 15 horas en la semana de referencia.

6 Porcentaje de la población ocupada no agropecuaria que se encuentra trabajando menos de 35 horas a la semana por razones de mercado, más la que trabaja más de 35 horas semanales con ingresos mensuales inferiores al salario mínimo, y la que labora más de 48 horas semanales ganando hasta dos salarios mínimos.
} 


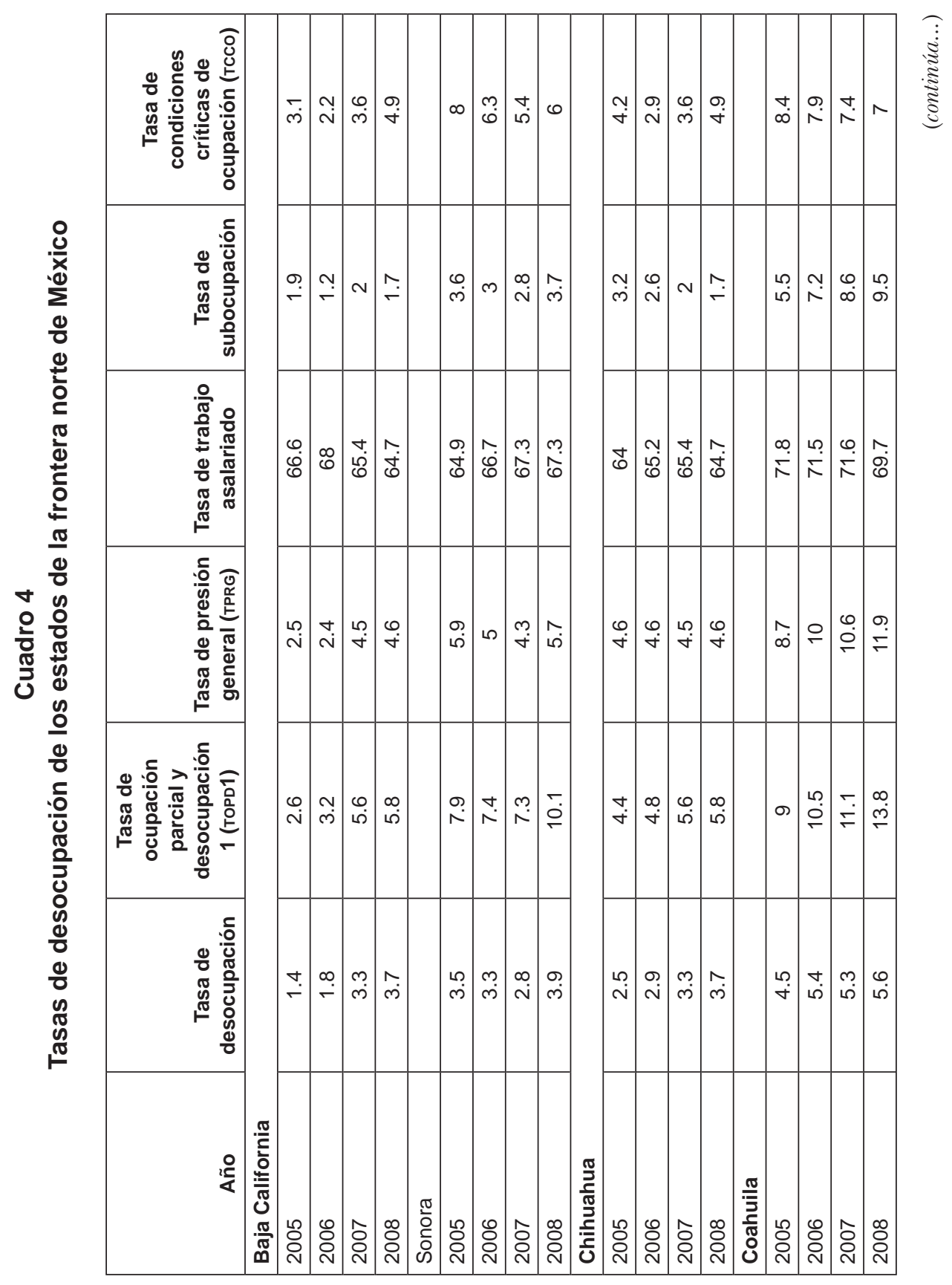




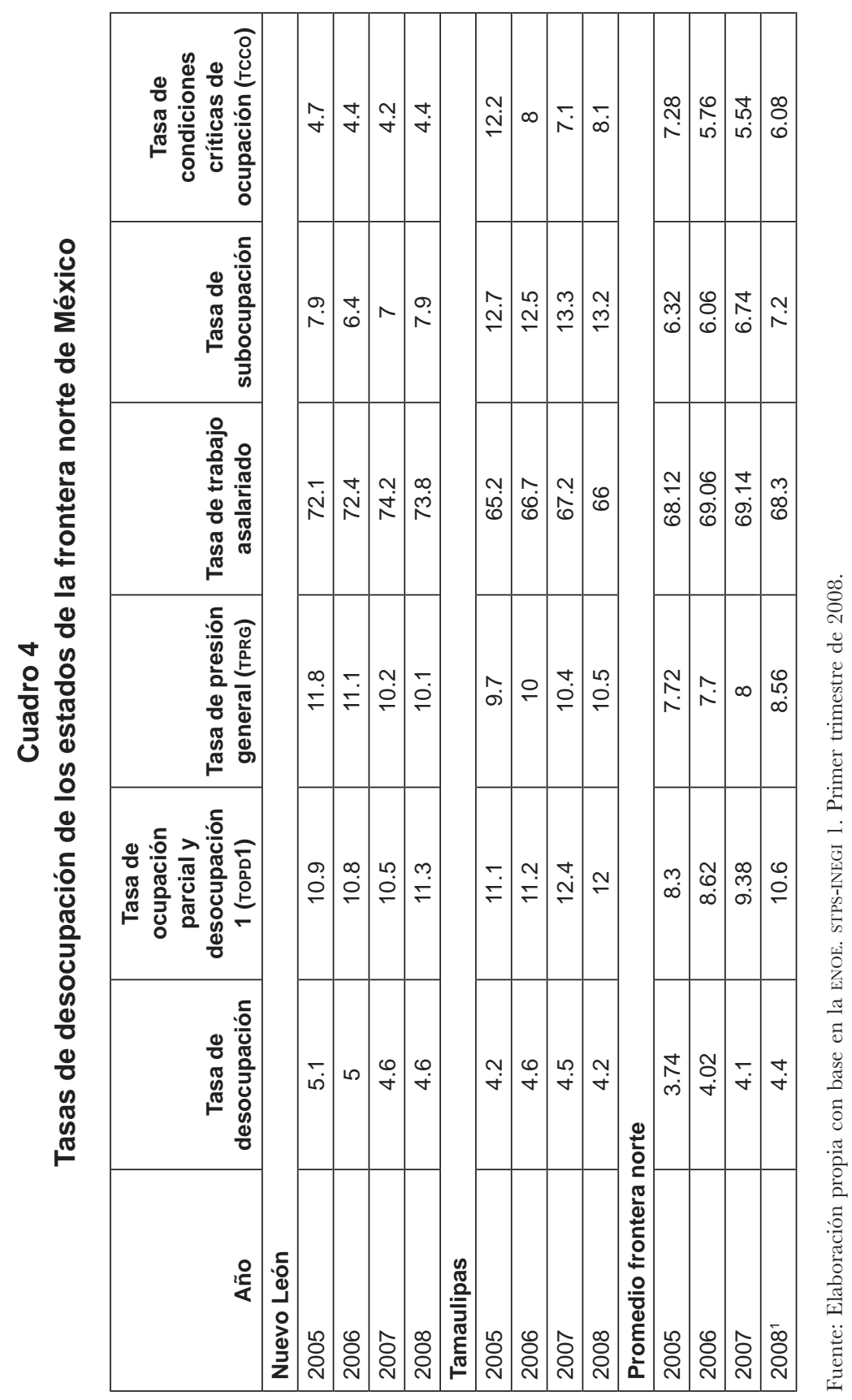


implicaba que las actividades del sector económico de la frontera norte no podrían generar la cantidad suficiente de empleos para ocupar a las personas que ingresan a la PEA.

\section{La industria manufacturera y la dinámica del empleo en la frontera norte}

La dinámica económica y manufacturera de los estados de la frontera norte de México ha estado directamente relacionada con el rápido crecimiento de las actividades económicas y el empleo en la frontera norte de México. Con el fin de estimar la diferencia del impacto del crecimiento económico basado en la dinámica económica, en este trabajo se emplea un modelo de estimación econométrica de panel con efectos aleatorios. ${ }^{7}$

El modelo considera que el crecimiento de las manufacturas impactó el crecimiento del empleo hasta antes de la recesión de 2008, particularmente en los estados de la frontera norte de México. Formalmente, el modelo se determina de la siguiente manera:

$$
E_{i t}=\alpha_{i t}+M_{i t}+D_{t}+\varepsilon_{i t}
$$

Donde $E_{i t}$ está conformado por el nivel de ocupación formal registrado por el Instituto Mexicano del Seguro Social (IMSs) para todos los estados de México, $i$, en el periodo, $t$, 2003-2007, $M$ es la proporción del producto interno bruto (РIв) manufacturero en el PIB total por estados para el periodo referido obtenido del Banco de Información Económica del INEGI, $D$ es una variable dicotómica que toma un valor de 1 para los estados de la frontera y 0 para el resto de los estados, y $e$ es el término de error.

Los resultados que se presentan en el cuadro 5 muestran que los coeficientes de las variables explicatorias fueron positivos y estadísticamente significativos. Lo anterior sugiere que el crecimiento de la actividad eco-

\footnotetext{
7 Este método estima una ecuación de una regresión "pooled" de forma: $\mathrm{Y}_{\mathrm{it}}=\alpha_{\mathrm{it}}+$ $\beta \mathrm{x}_{\text {it }}+\varepsilon_{\mathrm{it}}$. El modelo de afectos aleatorios asume que $\alpha_{i t}$ es la suma de una constante $\alpha$ que no varía en el tiempo a lo largo de la variable aleatoria $\varepsilon_{i t}$ que tiene un residual no correlacionado.
} 


\section{Cuadro 5}

Modelo de panel de efectos aleatorios

160 observaciones y 32 secciones cruzadas

Variable dependiente: crecimiento del empleo formal de asegurados

en el IMss

\begin{tabular}{|c|c|c|c|c|}
\hline Variable & Coeficiente & Error estándar & T estadístico & $\mathbf{P}$ \\
\hline const. & 363181 & 108016 & 3.362 & $0.00097^{* * *}$ \\
\hline DFN & 254293 & 206657 & 2.231 & $0.03035^{\star *}$ \\
\hline PIBS & 3422.76 & 360821 & 1.899 & $0.08244^{*}$ \\
\hline
\end{tabular}

Desviación estándar de la variable dependiente: 447890.

Suma de los residuos al cuadrado $=303$.

Criterio de información de Akaike (AIC) $=4614.85$.

Criterio Schwarz Bayesian $(\mathrm{BIC})=4624.07$.

Criterio Hannan-Quinn $(\mathrm{HQC})=4618.59$.

Test de Hausman-hipótesis nula: consistente con estimación GSL.

Test asintótico estadístico t: Chi cuadrada $(1)=0.322$.

DFN: Variable dicotómica para los estados de la frontera norte de México.

PIBs: Producto interno bruto de los estados de México.

*** Significativo al $1 \%$ de confianza, $* *$ significativo al $5 \%$ de confianza, * significativo al $10 \%$ de confianza.

nómica ha sido un determinante regional del crecimiento del empleo de los trabajadores registrados en el Seguro Social. No obstante, el resultado más importante es que el coeficiente de la variable dicotómica que representa el efecto del PIB de los estados de la frontera norte en el crecimiento regional ha mostrado un impacto superior al del total de los estados de la economía mexicana. Lo anterior permite suponer que la dinámica económica de los estados de la frontera norte, cuya especialización se ha centrado en el desarrollo de actividades de exportación, fundamentalmente orientadas a la exportación, ha tenido un efecto decisivo en el crecimiento de la región.

\section{La industria maquiladora en la frontera norte}

Existen diferentes estudios que han estimado el efecto del nivel de empleo en la industria maquiladora. Mendoza y Calderón (2001), Fullerton y Schauer (2001) y Mollick (2003) concluyen que la dinámica del empleo de 
la maquiladora está en función del tipo de cambio y la demanda y nivel de la actividad económica en Estados Unidos.

En todo caso, la industria maquiladora de exportación (IME) se caracterizó por un explosivo crecimiento del empleo, particularmente entre 1990 y 2000, cuando experimentó una tasa de crecimiento promedio anual de 10.9\%. En particular, los años de 1995, 1996 y 1997 presentaron tasas de crecimiento anual de $13.4 \%, 17.3 \%$ y $17.2 \%$ respectivamente (cuadro 6). No obstante, este sector, que se había convertido en el motor del crecimiento en la frontera norte, sostuvo una drástica caída del empleo en 2001 (18.2\%), recuperándose en 2004 (7.8\%), para mantenerse estancado desde entonces.

\section{Cuadro 6}

\section{Industria maquiladora de exportación (Total de empleo)}

\begin{tabular}{|c|c|c|}
\hline Periodo & $\begin{array}{c}\text { Total de empleados } \\
\text { de la IME }\end{array}$ & $\begin{array}{c}\text { IME: tasas de crecimiento } \\
\text { anual del empleo total }\end{array}$ \\
\hline $\mathbf{1 9 9 0}$ & 439,474 & $10.62 \%$ \\
\hline $\mathbf{1 9 9 1}$ & 486,146 & $4.91 \%$ \\
\hline $\mathbf{1 9 9 2}$ & 510,035 & $7.17 \%$ \\
\hline $\mathbf{1 9 9 3}$ & 546,588 & $9.88 \%$ \\
\hline $\mathbf{1 9 9 4}$ & 600,585 & $13.43 \%$ \\
\hline $\mathbf{1 9 9 5}$ & 681,251 & $17.34 \%$ \\
\hline $\mathbf{1 9 9 6}$ & 799,347 & $17.20 \%$ \\
\hline $\mathbf{1 9 9 7}$ & 936,825 & $11.39 \%$ \\
\hline $\mathbf{1 9 9 8}$ & $1,043,483$ & $14.56 \%$ \\
\hline $\mathbf{1 9 9 9}$ & $1,195,371$ & $9.59 \%$ \\
\hline $\mathbf{2 0 0 0}$ & $1,310,026$ & $-18.21 \%$ \\
\hline $\mathbf{2 0 0 1}$ & $1,071,488$ & $-0.33 \%$ \\
\hline $\mathbf{2 0 0 2}$ & $1,067,948$ & $-1.66 \%$ \\
\hline $\mathbf{2 0 0 3}$ & $1,050,210$ & $7.76 \%$ \\
\hline $\mathbf{2 0 0 4}$ & $1,131,726$ & $2.19 \%$ \\
\hline $\mathbf{2 0 0 5}$ & $1,156,477$ & $1.25 \%$ \\
\hline $\mathbf{2 0 0 6}$ & $1,170,962$ & $6.1 \%$ \\
\hline TCPA & & \\
\hline & & \\
\hline
\end{tabular}

Fuente: Elaboración propia con datos del INEGI. Estadística de la industria maquiladora de exportación. 
Cabe destacar que si bien la Ime generó un impulso significativo del empleo manufacturero en la frontera norte de México, por lo menos hasta el año de 2001, no se observó que este tipo de industria se desarrollara hacia procesos productivos que incidieran significativamente en la elevación de la calificación de la fuerza de trabajo en esta actividad económica. Así, entre 2000 y 2006 la participación porcentual de técnicos de producción en el total de trabajadores empleados en la IME se elevó de solamente $12.5 \%$ en el primer año a $13.4 \% 16$ años después (cuadro 7).

Respecto al nivel de calidad de los trabajos y su relación con el grado de calificación de la fuerza de trabajo, se puede abundar que el lento

\section{Cuadro 7}

Indicadores de empleo de técnicos de producción en la industria maquiladora de exportación

\begin{tabular}{|c|c|c|c|c|c|}
\hline Periodo & Total (1) & $\begin{array}{l}\text { Técnicos de } \\
\text { producción } \\
\text { (2) }\end{array}$ & $1 / 2$ & Hombres & Mujeres \\
\hline 1990 & 439,474 & 54,715 & $12.45 \%$ & & \\
\hline 1991 & 486,146 & 57,528 & $11.83 \%$ & & \\
\hline 1992 & 510,035 & 61,050 & $11.97 \%$ & & \\
\hline 1993 & 546,588 & 62,010 & $11.34 \%$ & & \\
\hline 1994 & 600,585 & 67,491 & $11.24 \%$ & & \\
\hline 1995 & 681,251 & 74,797 & $10.98 \%$ & & \\
\hline 1996 & 799,347 & 88,316 & $11.05 \%$ & & \\
\hline 1997 & 936,825 & 111,111 & $11.86 \%$ & $70.28 \%$ & $29.72 \%$ \\
\hline 1998 & $1,043,483$ & 126,859 & $12.16 \%$ & $70.94 \%$ & $29.06 \%$ \\
\hline 1999 & $1,195,371$ & 146,831 & $12.28 \%$ & $72.15 \%$ & $27.85 \%$ \\
\hline 2000 & $1,310,026$ & 159,452 & $12.17 \%$ & $72.51 \%$ & $27.49 \%$ \\
\hline 2001 & $1,071,488$ & 136,354 & $12.73 \%$ & $73.44 \%$ & $26.56 \%$ \\
\hline 2002 & $1,067,948$ & 139,615 & $13.07 \%$ & $73.50 \%$ & $26.50 \%$ \\
\hline 2003 & $1,050,210$ & 136,055 & $12.96 \%$ & $73.58 \%$ & $26.42 \%$ \\
\hline 2004 & $1,131,726$ & 144,111 & $12.73 \%$ & $73.36 \%$ & $26.64 \%$ \\
\hline 2005 & $1,156,477$ & 151,942 & $13.14 \%$ & $74.04 \%$ & $25.96 \%$ \\
\hline 2006 & $1,170,962$ & 156,991 & $13.41 \%$ & $73.80 \%$ & $26.20 \%$ \\
\hline
\end{tabular}

Fuente: Elaboración propia con datos del INEGI. Estadística de la industria maquiladora de exportación. 
crecimiento de empleos con mayores habilidades del trabajo ha estado acompañado por mecanismos que han apoyado, hasta cierto nivel, la capacitación del mismo.

Así, el nivel educativo previo de los trabajadores es predominantemente de seis años, aunque existe una proporción menor de trabajadores con niveles de secundaria o tecnológica (Carrillo, 2001). En efecto, la formación técnica de los trabajadores empleados en las maquiladoras proviene de centros educativos públicos, particularmente de escuelas secundarias (rama electrónica) y tecnológicos públicos (rama de autopartes).

Por lo que toca a la capacitación que se ofrece al nivel de planta en las maquiladoras, de acuerdo con el autor, los contenidos de los programas son en general (más de 60\%) orientados a temas organizativos y de administración y en menor medida en programas relacionados con las habilidades técnicas aplicadas a los procesos productivos. En esa medida, es posible señalar que si bien la industria maquiladora ha generado una mayor capacitación de la fuerza de trabajo, ésta aún no ha logrado traducirse en un cambio cualitativo de los niveles de calificación de los empleados de la industria maquiladora.

Finalmente, se destaca que la composición del empleo por género muestra que la industria maquiladora, que inicialmente se caracterizaba por emplear a un gran porcentaje de mujeres con bajas habilidades laborales, exhibió una constante reducción de la participación de las mujeres en el empleo total de $29.7 \%$ en el 2000 a 26.2\%. Lo anterior se deriva de la creciente participación de los hombres en estas actividades y del desarrollo de procesos productivos con un mayor grado de demanda de habilidades del trabajo.

Los factores que han permitido la expansión del empleo en las maquiladoras son los salarios relativamente más bajos pagados en México respecto a los de Estados Unidos, y las ventajas de localización geográfica derivadas de la cercanía respecto al mercado de este país. Asimismo, la depreciación del tipo de cambio ha generado que la productividad, medida en dólares, de los trabajadores en las maquiladoras creciera al 5.8\%, mientras que sólo lo hizo en $1.7 \%$, medida en pesos constantes, en el periodo 1990-2006. ${ }^{8}$

8 Estimaciones propias con información del Banco de Información Económica, INEGI. 
No obstante el auge de la maquiladora en los noventa, actualmente existen desafíos más importantes para la actividad productiva en la región de la frontera de México y Estados Unidos. Entre éstos, se destaca el acelerado crecimiento de las exportaciones de China hacia Estados Unidos. Aunque México ha continuado siendo uno de los principales socios comerciales del país del norte, el rápido crecimiento de las exportaciones de China ha sobrepasado las exportaciones mexicanas. Entre 1990 y 2006 el crecimiento de las exportaciones en dólares de China fue de $18.5 \%$ y el de México de $11.5 \%,{ }^{9}$ y desde 2003 China ocupó el lugar de México como segundo exportador a Estados Unidos.

Además, se destaca que en exportaciones como computadoras, equipo de telecomunicación, vidrio, muebles de cocina y otros, China ha sobrepasado a las mexicanas, que sin embargo son todavía predominantes en automóviles, motores, autopartes y televisores. Entre las ventajas comparativas que China tiene sobre México se encuentran los salarios por hora, relativamente más bajos, que en 1990 eran de 0.23 dólares por hora y representaban $10 \%$ de los mexicanos, incrementándose a un dólar en 2005, representando $2 \%$ del valor de los de México. ${ }^{10}$

Uno de los efectos del establecimiento del TLCAN ha sido la especialización de ciertas regiones y ramas productivas y la predominancia del dinamismo del empleo en las maquiladoras, caracterizado por empleos de poca calificación de la fuerza de trabajo. Esto ha permitido que en la frontera norte, particularmente en las ciudades que se encuentran a lo largo de la frontera con Estados Unidos, se hubiese mantenido una importante dinámica de empleo.

Un importante problema que presenta la generación de empleo mediante el crecimiento de la industria maquiladora se relaciona con la extrema volatilidad de la inversión en este sector, ya que en él, el capital se caracteriza por su alta movilidad internacional. Cualquier movimiento en salarios, regulaciones fiscales o el desarrollo de competidores en salarios

\footnotetext{
9 Estimaciones propias con información del U.S. Census Bureau, Foreign Trade Division, Data Dissemination Branch, Washington, D.C., 20233.

10 Estimaciones propias con información del National Bureau of Statistics of China, China Statistical Yearbook, 1996, 2004, 2006, y del Banco de Información Económica, INEGI.
} 
y eficiencia, como ha sido el caso de la economía china, puede generar una salida masiva de inversiones productivas y consiguientemente de empleo en el sector (Palma, 2003). Por ello, la creciente penetración de las exportaciones de China, conjuntamente con la recesión económica de la economía de Estados Unidos desde 2008, se presentan como factores negativos que inciden en esta actividad y por consecuencia en el panorama del empleo en la frontera norte de México.

\section{Análisis del empleo urbano en la región de la frontera norte de México}

\section{Crecimiento demográfico}

Las ciudades fronterizas se localizan a lo largo de la frontera con Estados Unidos o en una rango de distancia no mayor a los 200 kilómetros y están caracterizadas por su dinámica de crecimiento de la población. ${ }^{11}$

Dichas ciudades mostraron una tasa de crecimiento promedio anual de $2.7 \%$ entre 1990 y 2000. Los municipios donde se localizan las ciudades de la frontera norte que tuvieron el más rápido crecimiento de la población fueron Tijuana con 5.5\%, Ciudad Juárez con 4.2\%, Reynosa con $4.3 \%$, Nogales con $4 \%$ y Agua Prieta con 4.9\%. Lo anterior se relaciona, por un lado, con el dinamismo económico derivado del auge de la industria maquiladora, como es el caso de Tijuana y Ciudad Juárez, otro, con la migración de mexicanos hacia las ciudades fronterizas y la migración temporal con fines de cruce hacia Estados Unidos.

11 El conjunto de ciudades que se incluyen son las siguientes: Mexicali, Ensenada, Tecate, Guadalupe Victoria, Rodolfo Sánchez y Zona Metropolitana (zM) de Tijuana, en el estado de Baja California; Heroica Nogales, San Luis Río Colorado, Agua Prieta, Heroica Caborca, Cananea, Puerto Peñasco y Magdalena de Kino, en el estado de Sonora; Nuevo Casas Grandes, Manuel Ojinaga y zm de Ciudad Juárez, en el estado de Chihuahua; Ciudad Acuña, Sabinas, Allende y zm de Piedras Negras, en el estado de Coahuila; Ciudad Sabinas Hidalgo y Anáhuac, en el estado de Nuevo León; Valle Hermoso, Ciudad Miguel Alemán, zm de Reynosa-Río Bravo, zM de Matamoros y zm de Nuevo Laredo, en el estado de Tamaulipas. 
De acuerdo con las proyecciones del Conapo, el total de habitantes de las ciudades fronterizas casi se duplicará en el mismo periodo proyectado, pasando de un total de 6342245 habitantes a 11721814 en 2030. Este acelerado crecimiento impondrá la necesidad de generar mecanismos para el establecimiento de infraestructura social y urbana en un futuro cercano.

El aumento de la población de la región de la frontera norte está relacionado en particular con el crecimiento acelerado de las tres ciudades fronterizas más importantes: Tijuana, Ciudad Juárez y Mexicali. En conjunto, esas tres ciudades mostraron una notable expansión de la población: en el caso de Tijuana, esta ciudad prácticamente doblará la cifra de población entre 2000 y 2030, pasando de 1238157 habitantes a 2422071 en el periodo referido; por su parte, Ciudad Juárez también muestra el mismo patrón de crecimiento, por lo que se proyecta crecerá de 1255884 habitantes hasta $2406411 .^{12}$

En las ciudades de la frontera norte, la población de hombres y mujeres se concentra en el rango quinquenal de edades que va de los 0 a los 4 años y de los 5 a los 9 años con $11.4 \%$ y $11.1 \%$ y $10.9 \%$ y $10.6 \%$ para cada género respectivamente. En el rango de 15 a 19 años, se observa una disminución de la participación en el total, cayendo al $9.3 \%$ y al $9.1 \%$, para elevarse nuevamente en el rango de 20 a 24 años. No obstante, en el caso de la población por edades, a nivel nacional la población de hombres y mujeres en los mismos rangos de edad mostró una declinación del porcentaje de población a medida que se incrementan los años; es decir, de 0 a 4 años la participación fue de $11.9 \%$ y $11.1 \%$, de 5 a 19 años de $10.3 \%$ y $10.2 \%$, y de 20 a 24 años de $9 \%$ y $9.6 \%$, para hombres y mujeres respectivamente. ${ }^{13}$

La diferencia en la pirámide poblacional puede estar ocasionada por la migración interna hacia las ciudades de la frontera norte. Cabe destacar que los cinco primeros rangos quinquenales acumulaban $49.3 \%$ y $48.3 \%$ de la población total en esas ciudades fronterizas. Este fenómeno se adiciona al

\footnotetext{
12 Estimaciones propias con base en el IneGI, XI y XII Censos Generales de Población y Vivienda, 1990 y 2000.

13 Estimaciones propias con base en el Inegi, XII Censo General de Población y Vivienda, 2000.
} 
crecimiento de la población local generando más presiones en el mercado laboral por parte de la PEA que busca obtener empleo en la región.

Así, las ciudades de la frontera también pueden ser agrupadas por sus diferencias en cuanto a las características migratorias de la población que habita en ellas. Al respecto, se destacan las ciudades que se caracterizaron por tener un mayor nivel de participación de la población no nacida en las entidades fronterizas, como Playas de Rosarito, Tijuana, Tecate y Ensenada en el estado de Baja California, que tuvieron un nivel de población que nació en esa entidad menor al 50 por ciento. ${ }^{14}$

De esta manera, ciudades de la frontera norte se caracterizan por contar con un nivel importante de población que se incorpora a partir de los procesos migratorios. Asimismo, algunas de las ciudades de la frontera norte experimentan un flujo superior de emigración de parte de su población, lo cual tiene un impacto adicional que presiona el mercado laboral para generar mayor empleo.

\section{Aspectos económicos}

El impacto del crecimiento económico y de la población ha tenido implicaciones para la economía mexicana en lo relativo a los niveles de ingreso per cápita, los mercados de trabajo y la localización de la actividad económica. En lo que toca al ingreso per cápita, los más elevados de las ciudades fronterizas se localizan en Tijuana, Ciudad Juárez y Ojinaga, con niveles estimados de 14.493, 13.469 y 13.079 dólares, respectivamente. El promedio de ingreso para las ciudades fronterizas era de 8.609 dólares con una desviación estándar de 2.167 dólares, siendo el promedio a nivel nacional de 7.495 dólares (cuadro 8).

El total de la población ocupada en las ciudades fronterizas del norte más importantes representaba $6.6 \%$ del total del empleo del país, y su tasa de crecimiento promedio anual entre 1990 y 2000 fue de $4.9 \%$. Asimismo resalta la importancia que tienen las actividades manufactureras en este tipo de ciudades, con $11.7 \%$ del total del empleo nacional en 2000. También se aprecia que este tipo de empleo ha crecido signi-

14 Estimaciones propias con base en el Inegi, XII Censo General de Población y Vivienda, 2000. 
Cuadro 8

Ciudades de la frontera: ingreso per cápita de las ciudades fronterizas

\begin{tabular}{|l|c|}
\hline \multicolumn{1}{|c|}{ Municipio } & $\begin{array}{c}\text { Ingreso per cápita } \\
\text { anual municipal } \\
\text { (dólares ppc) }\end{array}$ \\
\hline Tijuana & $14,493.80$ \\
\hline Ciudad Juárez & $13,469.42$ \\
\hline Ojinaga & $13,079.01$ \\
\hline Mexicali & $13,063.02$ \\
\hline Ensenada & $11,886.64$ \\
\hline Nogales & $11,856.95$ \\
\hline Sabinas Hidalgo & $11,577.27$ \\
\hline Hidalgo & $11,333.04$ \\
\hline Nuevo Laredo & $10,888.23$ \\
\hline Allende & $10,745.44$ \\
\hline Acuña & $10,411.24$ \\
\hline Sabinas & $10,226.12$ \\
\hline Matamoros & $10,128.65$ \\
\hline Reynosa & $9,980.03$ \\
\hline Nuevo Casas Grandes & $9,422.81$ \\
\hline Agua Prieta & $9,155.57$ \\
\hline San Luis Río Colorado & $9,127.94$ \\
\hline Cananea & $9,019.72$ \\
\hline Magdalena & $8,594.62$ \\
\hline Anáhuac & $8,560.83$ \\
\hline Caborca & $8,048.63$ \\
\hline Puerto Peñasco & $7,980.09$ \\
\hline Casas Grandes & $7,260.95$ \\
\hline Miguel Alemán & $6,720.06$ \\
\hline Navojoa & $5,970.36$ \\
\hline Desviación Estándar & $2,167.83$ \\
\hline & \\
\hline & \\
\hline
\end{tabular}

Fuente: Conapo, Índice de Desarrollo Humano Municipal. 
ficativamente en estas ciudades, con una tasa promedio anual de $6.5 \%$. Otras actividades económicas de importancia, dado su peso en el empleo ocupado, son servicios de restaurantes y hoteles, electricidad y agua, construcción, extracción de petróleo y servicios personales y el comercio (cuadro 9).

En el caso de la frontera norte, se aprecia que, en promedio, la población de las ciudades fronterizas se concentra en trabajos del sector manufacturero. De acuerdo con los índices de localización construidos para

\section{Cuadro 9}

Población ocupada por actividad económica (Frontera norte, 2000)

\begin{tabular}{|l|c|c|c|}
\hline \multicolumn{1}{|c|}{ Sector de actividad } & $\begin{array}{c}\text { Estructura } \\
\text { porcentual, } \\
\mathbf{2 0 0 0}\end{array}$ & $\begin{array}{c}\text { Participación } \\
\text { porcentual en el } \\
\text { nacional, 2000 }\end{array}$ & $\begin{array}{c}\text { Tasa de } \\
\text { crecimiento, } \\
\mathbf{1 9 9 0 - 2 0 0 0}\end{array}$ \\
\hline Total & $100.00 \%$ & $6.60 \%$ & $4.85 \%$ \\
\hline $\begin{array}{l}\text { Agricultura, ganadería, silvicultura y } \\
\text { pesca }\end{array}$ & $8.50 \%$ & $2.01 \%$ & $-0.83 \%$ \\
\hline Minería & $0.45 \%$ & $6.17 \%$ & $-0.09 \%$ \\
\hline Extracción de petróleo y gas & $0.53 \%$ & $6.96 \%$ & $-7.32 \%$ \\
\hline Industria manufacturera & $28.62 \%$ & $11.72 \%$ & $6.51 \%$ \\
\hline Electricidad y agua & $0.82 \%$ & $7.63 \%$ & $0.19 \%$ \\
\hline Construcción & $7.57 \%$ & $6.45 \%$ & $5.04 \%$ \\
\hline Comercio & $15.12 \%$ & $6.05 \%$ & $4.99 \%$ \\
\hline Transportes y comunicaciones & $4.36 \%$ & $6.00 \%$ & $4.63 \%$ \\
\hline Servicios financieros & $1.55 \%$ & $6.16 \%$ & $2.03 \%$ \\
\hline Administración pública y defensa & $3.40 \%$ & $4.73 \%$ & $3.53 \%$ \\
\hline Servicios comunales y sociales & $7.48 \%$ & $5.07 \%$ & $3.76 \%$ \\
\hline Servicios profesionales y técnicos & $2.33 \%$ & $5.86 \%$ & $5.41 \%$ \\
\hline Servicios de restaurantes y hoteles & $4.96 \%$ & $7.50 \%$ & $5.13 \%$ \\
\hline Servicios personales y mantenimiento & $10.60 \%$ & $6.49 \%$ & $4.62 \%$ \\
\hline No especificado & $3.70 \%$ & $9.48 \%$ & $6.39 \%$ \\
\hline
\end{tabular}

Fuente: Elaboración propia con datos de los Censos Generales de Población y Vivienda 1990 y 2000, INEGI. 
las ciudades de la frontera, ${ }^{15}$ en promedio las ciudades localizadas en la frontera norte mostraron un índice de especialización de 1.78 en el sector manufacturero, seguido del sector de electricidad y agua y el de servicios de restaurantes y hoteles con 1.16 y 1.14 respectivamente (cuadro 10).

\section{Estructura del empleo}

\section{Población económicamente activa según su situación laboral}

La distribución de la PEA en cuanto a la situación del trabajo mostró que en el año 2000 el $75.2 \%$ de los trabajadores eran empleados y obreros en las ciudades de la frontera norte. Este aspecto implica una importante necesidad de generar trabajo asalariado para este tipo de trabajadores que son predominantes a lo largo de la frontera norte de México. En relación con el tipo de ocupaciones predominantes en las ciudades fronterizas, se aprecia que en las ciudades de la frontera norte la mayor proporción de trabajadores se concentraba en la categoría operación de maquinarias con $17 \%$ del total, siendo el porcentaje aún más alto para las mujeres, con 24.9 por ciento. ${ }^{16}$

Siguieron en importancia los comerciantes y dependientes con $11 \%$, los oficinistas con $7.3 \%$ y los trabajadores en servicios con 6\%. Por ello, se puede concluir que en este tipo de ocupaciones los empleados deben buscar mejorar sus habilidades laborales a fin de buscar adicionar mayor agregado a la producción y estar en condiciones de recibir salarios mejor remunerados.

15 La fórmula para calcular el índice de localización es IL=(ei/e)/(Ei/E).

Donde:

ei $=$ Empleo local en las actividades económicas i.

e = Población ocupada local.

$\mathrm{Ei}=$ Empleo nacional en las actividades i.

$\mathrm{E}=$ Población ocupada en el país.

16 Estimación propia con base en el Inegi, XII Censo General de Población y Vivienda, 2000. 


\section{Cuadro 10 \\ Índice de especialización de las ciudades de la frontera norte}

\begin{tabular}{|l|c|c|}
\hline & $\begin{array}{c}\text { Índice de } \\
\text { especialización }\end{array}$ & $\begin{array}{c}\text { Participación } \\
\text { porcentual en el } \\
\text { nacional }\end{array}$ \\
\hline Total ciudades fronterizas & & 6.60 \\
\hline 10 Agricultura, ganadería, silvicultura y pesca & 0.305 & 2.01 \\
\hline 20 Minería & 0.935 & 6.17 \\
\hline 20b Extracción de petróleo y gas & 1.055 & 6.96 \\
\hline 31-32 Industria manufacturera & 1.776 & 11.72 \\
\hline 41 Electricidad y agua & 1.156 & 7.63 \\
\hline 42 Construcción & 0.978 & 6.45 \\
\hline 50 Comercio & 0.917 & 6.05 \\
\hline 60 Transportes y comunicaciones & 0.909 & 6.00 \\
\hline 70 Servicios financieros & 0.933 & 6.16 \\
\hline 81 Administración pública y defensa & 0.718 & 4.73 \\
\hline 82 Servicios comunales y sociales & 0.769 & 5.07 \\
\hline 83 Servicios profesionales y técnicos & 0.889 & 5.86 \\
\hline 84 Servicios de restaurantes y hoteles & 1.137 & 7.50 \\
\hline 85 Servicios personales y mantenimiento & 0.983 & 6.49 \\
\hline 99 No especificado & 1.437 & 9.48 \\
\hline
\end{tabular}

Fuente: Elaboración propia con datos del IneGi, Censo de Población 2000.

\section{Políticas laborales y empleo en la frontera México-Estados Unidos}

Como se señaló previamente, las principales características del mercado laboral mexicano son el rápido crecimiento de la fuerza laboral, que presiona a la generación de empleos e incentiva los flujos migratorios hacia Estados Unidos, el bajo nivel de la tasa de desocupación abierta, que refleja niveles importantes de ocupación formal pero también la concentración del fenómeno de la informalidad, y la concentración de la dinámica del empleo en el sector manufacturero en la frontera norte de México. 
Ante esta situación, las políticas del mercado de trabajo son un importante instrumento de política económica y social que contribuye a conectar la oferta y demanda del mismo y mejorar la fuerza de trabajo desocupada en un contexto de apertura y cambio estructural de la economía mexicana. Cabe destacar que una importante cantidad de recursos se ha canalizado hacia la creación directa e indirecta de empleo y la capacitación de la fuerza de trabajo, aunque se aprecia una carencia de seguro de desempleo (Samaniego, 2002).

En lo que corresponde a la creación de empleo, las políticas laborales del gobierno federal y estatal se han fundamentado en dos vertientes: los subsidios al empleo o salario y la creación directa de empleo. Respecto a la primera modalidad, a partir de 1995, como resultado de la recesión económica, se impulsaron medidas para alentar la contratación de trabajadores mediante el uso de estímulos fiscales a empresas formales (créditos fiscales contra el impuesto sobre la renta).

Respecto a las políticas laborales estatales, a partir de 1996 se establecieron medidas para reducir el desempleo derivado de la recesión económica que redujo el gasto público en proyectos de infraestructura debido a una declinación de la inversión privada y pública nacional. Los mecanismos de promoción del empleo se fundamentaron en exenciones de impuestos sobre nóminas por concepto de empleos adicionales y subsidios sobre el impuesto predial a nuevas empresas que hubieran empleado más de cien personas. Asimismo, se establecieron programas como el PET (Programa de Empleo Temporal), particularmente orientado a impulsar obras intensivas en mano de obra en las zonas rurales marginadas.

El mecanismo más importante para promover el empleo se deriva del Servicio Nacional de Empleo (SNE) creado en 1978. Dicho programa sirve como mecanismo de intermediación laboral para promover la colocación de trabajadores en los empleos existentes, capacitar a los desempleados y estudiar los mercados laborales (Ley Federal del Trabajo, 2001). El sistema cuenta con una red de oficinas de colocación para orientar a los trabajadores y además con un registro de puestos vacantes de las empresas del sector formal. Los programas son llevados a cabo en los estados con apoyo de recursos de la Secretaría del Trabajo y Prevención Social (sTPS) y los gobiernos estatales. Las principales actividades de colocación son las ferias 
del empleo, los talleres de desempleados y las bolsas de trabajo que sirven de instrumentos de intermediación (Chambatel y Chambanet). ${ }^{17}$

Respecto a la promoción del empleo de manera indirecta, mediante la capacitación de la fuerza de trabajo el gobierno ha intentado diversos programas con carácter temporal, establecidos para manejar los niveles de desempleo generados por las políticas de ajuste y las crisis económicas iniciadas durante la década de los ochenta. Éste es el caso del Probecat (Programa de Becas para la Capacitación de los Trabajadores), que inició los programas de capacitación, y más recientemente del Sistema de Capacitación para el Trabajo (Sicat), que desde los ochenta se ha consolidado como un instrumento de política de capacitación del mercado de trabajo. Este sistema es operado por los servicios de empleo (SEE) de los gobiernos de los estados, también con apoyo de recursos por parte de la sTPS.

De esta manera, a nivel nacional, las políticas de empleo no han podido compensar la falta de dinamismo de la creación de empleo derivada del creciente aumento de la PEA, y por otra parte, no han podido sustituir el cierre de empresas públicas y privadas que ha derivado en un estancamiento relativo de la oferta de empleos (Jiménez, 2005).

$\mathrm{Al}$ analizar las políticas de apoyo al empleo en los estados de la frontera norte de México, se observa que en Baja California se cuenta con programas de capacitación de la fuerza de trabajo relacionados con las necesidades de la industria, con el fin de que los graduados de universidades y escuelas técnicas tengan mejores oportunidades de conseguir empleos. Dichos programas están orientados hacia los técnicos electricistas, inglés en negocios y otros. Asimismo, la Secretaría del Trabajo estatal administra, como ya se señaló, los programas de servicio de empleo, el Sistema Estatal de Empleo (Siee), Chambanet, bolsas de trabajo, servicio de empleo y localización de talleres de trabajo con la Universidad Autónoma de Baja California, técnicos metalmecánicos con Kenworth, etcétera.

Por su parte, Nuevo León cuenta con tres Centros de Intermediación Laboral (CIL) equipados con computadora, teléfono, fax e Internet para que los trabajadores puedan estar en contacto con empresas. En Nuevo

17 Son mecanismos para que los trabajadores en busca de empleo puedan tener acceso a bases de datos sobre empleo disponibles por teléfono y por Internet. 
León también existe el Consejo de Relaciones Laborales y Productividad, que a través del Servicio Nacional de Empleo (SNE) pone a disposición el programa BÉCATE y brinda capacitación de uno a tres meses para técnico o administrativo para el sector productivo, capacitación para autoempleo, etcétera. Dicha beca incluye materiales de capacitación, asesoría del instructor-monitor, ayuda de transporte, seguro de accidentes y otros beneficios. Ambos programas se realizan a través del SNE.

Adicionalmente, se cuenta con el Instituto de Capacitación y Educación en el Trabajo, que cuenta con diversos planteles que ofrecen cursos de máquinas-herramientas, control numérico computarizado, electricidad industrial, mantenimiento industrial, operador de calderas y muchos otros. Dichos programas de capacitación son manejados por la Dirección de Capacitación y Competitividad del gobierno del estado.

En Tamaulipas, la Secretaría de Desarrollo Urbano y Empleo ofrece colocación para buscadores de empleo activos (Bolsa de Trabajo), feria del empleo (vacantes ofrecidas por las empresas en un mismo día y espacio físico), talleres para la búsqueda de empleo (técnicas para solicitantes con dificultades para colocarse), Comités Regionales de Capacitación y Empleo (vinculación con el sector productivo para detectar necesidades de capacitación) y Sistema de Empleo. Además, existen cursos de capacitación que se llevan a cabo en todo el estado. ${ }^{18}$

En Sonora, el Sicat ofrece ayuda para las personas en busca de empleo dando apoyo en capacitación sobre la base de requerimientos específicos de las empresas, apoyo a los micro y pequeños empresarios con personal que se capacitará en su establecimiento, y apoyo a aquellos grupos en una actividad productiva que requieran capacitación. Los apoyos consisten en una beca de uno a tres salarios mínimos mientras dura el curso, ayuda para transporte y pago de instructor.

Las políticas de apoyo al empleo se han convertido en un importante instrumento de política económica y social que ha permitido abordar la problemática del empleo derivada de los cambios estructurales de la economía mexicana desde la década de los ochenta. Los sistemas de apoyo

18 Las especialidades de estos cursos van desde panadería, peluquería, plomería, manualidades, corte y confección, instalaciones eléctricas y carpintería, hasta especialidades que las empresas requieran actualizar. 
al empleo señalados han canalizado importantes recursos del Estado para combatir el desempleo, aunque no se ha logrado consolidar una política orientada a proporcionar un seguro de desempleo. Además, dichos programas han sido concebidos como de carácter temporal y han servido solamente para compensar el desempleo generado por los cambios económicos y el impacto de la economía internacional en la economía mexicana.

\section{Conclusiones}

La estrategia de crecimiento económico de México basado en las exportaciones manufactureras orientadas hacia Estados Unidos y de captación de la IED proveniente en su mayor parte de este país ha tenido un impacto importante en el mercado laboral de México.

A escala nacional, el crecimiento promedio anual de la población económicamente activa ha presionado el mercado laboral, lo que ha derivado en el crecimiento de las actividades económicas realizadas mediante el empleo informal, el aceleramiento de los flujos de trabajadores mexicanos que migran hacia la frontera norte para cruzar hacia Estados Unidos, y la migración de trabajadores del interior del país a la frontera norte, atraída por el aumento del dinamismo del empleo formal en las actividades manufactureras.

El motor del crecimiento del empleo en la frontera norte de México se relaciona con el establecimiento de empresas manufactureras bajo el régimen de maquiladoras establecidas a lo largo de la frontera norte, lo que se corrobora en el modelo econométrico de panel estimado. Se destaca que las ciudades que conforman la región fronteriza de los estados muestran una mayor participación del empleo manufacturero, como es el caso de Ciudad Juárez, Tijuana y Reynosa.

La maquiladora se ha caracterizado por un explosivo crecimiento del empleo en la frontera norte, particularmente entre 1990 y 2000, periodo en que presentó una tasa de crecimiento promedio anual muy acelerada, aunque a partir de 2001 (año de drástica caída) se observa un estancamiento, derivado de la menor actividad económica de Estados Unidos y de la creciente competencia por el mercado estadounidense para la exportación de productos manufacturados, particularmente en las grandes plantas manufactureras del país (Kaplan, Martínez y Robertson, 2007). 
Como resultado de la dinámica económica de la frontera norte, las tasas de desempleo abierto en esta zona norte han sido menores a las de otras regiones de México.

No obstante, también existe presión derivada de la creciente incorporación de personas a la PEA. Por ello, existen tasas importantes de ocupación parcial y desocupación.

En este contexto de heterogeneidad de la actividad económica a nivel empresarial, sectorial y regional, las políticas laborales estatales se orientaron hacia la reducción del desempleo derivado de la recesión económica, que redujeron significativamente el gasto público en proyectos de infraestructura y de educación. Generalmente, los mecanismos de promoción del empleo se fundamentaron en programas como el PET (Programa de Empleo Temporal), particularmente orientado a impulsar obras intensivas en mano de obra en las zonas rurales marginadas y en mecanismos para promover el empleo que se derivan del Servicio Nacional de Empleo.

De esta forma, las políticas de empleo de corte nacional han sido concretadas a nivel estatal con pequeñas diferencias, pero en cada estado se han orientado en lo fundamental hacia la promoción de programas de capacitación de la fuerza de trabajo, de acuerdo a las necesidades de la industria, con el fin de que los graduados de universidades y escuelas técnicas tengan más oportunidades de conseguir mejores empleos. Asimismo, se cuenta con programas de intermediación para la colocación de trabajadores en empleos ofrecidos por el sector privado.

Resaltan por su mayor esfuerzo de capacitación los estados de Baja California y Nuevo León, los cuales ofrecen capacitaciones vinculadas a necesidades específicas de las empresas, particularmente en las áreas de técnicos metalmecánicos, de máquinas-herramientas, control numérico computarizado, electricidad industrial, mantenimiento industrial, operador de calderas, administrativo para el sector productivo y autoempleo.

Las políticas de empleo han sido un importante instrumento de política económica y social mediante programas de apoyo al empleo que han canalizado importantes recursos del Estado. Sin embargo, sólo han logrado combatir el desempleo temporalmente, ya que su naturaleza les impide impactar de manera más efectiva el problema del desempleo. 
Por tanto, la heterogeneidad del sector productivo en México ha determinado una imposibilidad de dinamizar al conjunto de la economía, siendo las empresas manufactureras de exportación las que han logrado una mayor generación de empleo. No obstante, el limitado desarrollo de cadenas productivas ha determinado que la posibilidad de incrementar el empleo con mayores niveles de valor agregado esté relacionada con las necesidades de las empresas de exportación o maquiladoras.

De esta manera, las posibilidades de generación de empleo de una mayor calificación, que permita elevar el valor agregado de los trabajadores, se relacionan con las nuevas formas de organización del trabajo para elevar la competitividad y productividad del mismo que implican mayor flexibilidad. Por otra parte, la posibilidad de estar en condiciones de generar empleo va más allá de realizar cursos de capacitación de la fuerza de trabajo, requiriendo un mayor esfuerzo para instrumentar sistemas educativos que estén más acordes con las necesidades de las empresas y la generación de capacitación relacionada con las posibilidades de crear pequeñas empresas que generen autoempleo.

\section{Bibliografía}

Carrillo, Jorge (2001), Mercados de trabajo en la industria maquiladora, México, El Colegio de la Frontera Norte, Plaza y Valdés.

Cortez Willy y Alejandro Islas, (2007), "¿Ha inducido cambios el TLCAN en la conducta de los salarios mexicanos?”, en Jorge Eduardo Mendoza (coord.), El TLCAN y la frontera México-Estados Unidos: aspectos económicos, México, El Colegio de la Frontera Norte, Miguel Ángel Porrúa.

Hanson, Gordon (2003), "What has Happened to Wages in Mexico since NAFTA? Implications for Hemispheric Free Trade", National Bureau of Economic Research (NBER), documento de trabajo, 9563, marzo.

Frenkel Roberto y Jaime Ros (2004), "Desempleo, políticas macroeconómicas y flexibilidad del mercado laboral. Argentina y México en los noventa", Desarrollo Económico, vol. 44, núm. 173, pp. 33-56.

Fullerton, T. y D. Schauer (2001), "Short-run: Maquiladora Employment Dynamics", International Advances in Economic Research, núm 7, pp. 471-478.

Gruben, W. (2001), Was NaFTA behind Mexico's high Maquiladora Growth?”, Econ. Financial Review, Federal Reserve Board of Dallas, Third Quarter: 11-21.

Kaplan, David, Gabriel Martínez y Raymond Robertson (2007), "Mexican Employment Dynamics: Evidence from Matched Firm-Worker Data", World 
Bank Financial Private Sector Development Department Enterprise Analysis Unit, Policy Research Working Paper 4433.

Jiménez, Alejandro (2005), "Las políticas de empleo en México y el desarrollo regional”, Aportes, vol. X, núm. 29, pp. 25-43.

López, Julio (2002), "Modernization, Heterogeneity and Employment in Mexico", International Review of Applied Economics, vol. 16, núm. 2.

Malacon, Cristina y Pilar Expositi (2003), Effects of the Integration of Mexico into NAFTA on Trade, Industry, Employment and Economic Growth, University of Santiago de Compostela, Faculty of Economics. Econometrics, Working Paper Series Economic Development, núm. 68.

Mendoza, Eduardo y Cuauhtémoc Calderón (2001), “Determinantes regionales de la maquila de exportación en la frontera norte”, Comercio Exterior, marzo, pp. 196-202.

Meza, Liliana (2005), "Mercados laborales locales y desigualdad salarial en México”, El Trimestre Económico, núm. 285, enero-marzo, pp. 133-178.

Mollick, A. (2003), "Employment Determination at Mexican Maquiladoras: Does Location Matter?", Journal Borderland Studies, 18(2):45-67.

Palma, Gabriel (2003), Trade Liberalization in Mexico: Its Impact on Growth, Employment and Wages, Employment Sector, International Labour Office Geneva, Employment Paper, 2003/55.

Revenga, Ana (1995), Employment and Wage Effects of Trade Liberalization, the Case of the Mexican Manufacturing, The World Bank, Latin American and Caribbean Country Department, Policy Research Working Paper 1524.

Robertson, Raymond (2000), "Wage Shocks and North American Labor Market Integration", The American Economic Review, vol. 90, núm. 4, septiembre, pp. 742-764.

Samaniego, Norma (2002), Las políticas de mercado de trabajo en México y su evaluación, Serie macroeconomía del desarrollo, Naciones Unidas, CEPAL.

Zadia, M. Feliciano (2001), "Workers and Trade Liberalization: The Impact of Trade Reforms on Wages and Employment", Industrial and Labor Relations Review, vol. 55, núm, 1, pp. 95-115.

Artículo recibido en diciembre de 2008 Segunda versión recibida en noviembre de 2009

Artículo aprobado en diciembre de 2009 